\title{
Contributing Roles of Depression, Anxiety, and Impulsivity Dimensions in Eating Behaviors Styles in Patients Suffering From Obesity and Seeking Bariatric Surgery
}

FARID BENZEROUK ( $\square$ benzeroukf@yahoo.fr)

EPSM Marne https://orcid.org/0000-0002-6469-6890

Monique Guenin

Etablissement Public de Santé Mentale Morbihan: EPSM Morbihan

\section{Fabien Gierski}

URCA: Universite de Reims Champagne-Ardenne

Delphine Raucher-Chéné

EPSMM

\section{Sarah Barrière}

CHU Reims: Centre Hospitalier Universitaire de Reims

\section{Eric Bertin}

CHU Reims: Centre Hospitalier Universitaire de Reims

Arthur Kaladjian

EPSMM

\section{Research Article}

Keywords: Obesity, Impulsivity, Eating behaviors styles, (Lack of) Perseverance, Urgency, Bariatric surgery

Posted Date: July 1st, 2021

DOI: https://doi.org/10.21203/rs.3.rs-650918/v1

License: (c) (1) This work is licensed under a Creative Commons Attribution 4.0 International License. Read Full License 


\section{Abstract}

Background: Even if bariatric surgery is considered the most effective therapeutic approach, it is not equally successful among individuals suffering from severe obesity and candidates for this weight loss surgery. Among the factors that influence postsurgical outcomes, eating behaviors styles are known to play a key role in relapses. The aim of our study was to assess eating behaviors styles and several modulating psychopathological factors in patients suffering from obesity.

Methods: Patients seeking bariatric surgery $(\mathrm{N}=127)$ completed a set of standardized tools assessing eating behaviors (Dutch Eating Behavior Questionnaire), comorbid psychiatric conditions (Mini International Neuropsychiatric Interview), depression, and anxiety scores (Beck Depression Inventory, State-Trait Anxiety Inventory), and impulsivity scores (UPPS-P Impulsive Behavior Scale).

Results: We detected significant correlations between DEBQ Emotional Eating (EmoE) and depression, state and trait anxiety, and all dimensions of impulsivity. Significant correlations were also present between DEBQ External Eating (ExtE) and depression, state and trait anxiety and UPPS-P positive urgency, lack of perseverance and sensation seeking. Regression analyses identified sex (female), trait anxiety, and lack of perseverance as explanatory factors for EmoE, and depression severity score and positive urgency for ExtE.

Conclusions: EmoE might be a means of dealing with negative emotions and/or intrusive thoughts, while ExtE might result from a mechanism associated with depression. These results should help to improve patients' outcomes by defining specific therapeutic targets in psychological interventions.

\section{Plain English Summary}

After bariatric surgery, some patients regain weight. This is likely due to various factors, including a return of maladaptive eating styles, such as emotional eating (which occurs as a response to negative emotions, like depression, anxiety, anger, sadness, and discouragement), external eating (which refers to the tendency to eat in response to positive external cues, regardless of internal signals of hunger and satiety), and restraint eating (implying to make efforts to develop and maintain strategies to control calories intake, associated with weight loss after lifestyle intervention). Our goal in this research project is to explore associated factors (particularly depression, anxiety, and impulsivity) to these eating styles in patients suffering from obesity prior to bariatric surgery.

Individuals seeking bariatric surgery were asked questions about their eating styles and their levels of depression, anxiety, and impulsivity using standardized questionnaires. We found that emotional eating might be a means of dealing with negative emotions and/or intrusive thoughts, while external eating might result from a mechanism associated with depression. We detected no association between restraint eating and any of the dimensions of impulsivity, nor depression and anxiety. Therapies aimed at improving patients' abilities to regulate negative affects seem promising among subjects suffering from obesity and those seeking bariatric surgery. If well learned, these therapies might also help them to maintain weight loss after surgery by limiting maladaptive eating styles.

\section{Background}

Obesity is now recognized as having reached an epidemic level worldwide and is associated with many serious diseases in developed countries. In 2014, more than 1.9 billion adult individuals were overweight, and 600 million were obese (defined as those having a body mass index (BMI) greater than or equal to $30 \mathrm{~kg} / \mathrm{m}^{2}$ ) [1]. Individuals with $\mathrm{BMI}^{3} 35 \mathrm{~kg} / \mathrm{m}^{2}$ (grade 2 obesity) with at least one comorbid condition and those with BMI ${ }^{3} 40 \mathrm{~kg} / \mathrm{m}^{2}$ (grade 3 obesity) can benefit from bariatric surgery, which is considered the most effective weight loss treatment [2]. Indeed, an average of 50\% of excess weight may be lost in the first few years after bariatric surgery, which secondary improves comorbidities like diabetes mellitus and cardiovascular events [3-6]. However, bariatric surgery is not equally effective in all patients, and many factors influencing long-term postsurgical outcomes are still to be understood in this population in which high rates of psychopathology have been reported [7].

Among these factors, eating behaviors styles may play a key role in success after weight loss surgery [8]. Indeed, Bryant et al. (2020) suggested that the level of disinhibition, restraint, hunger, emotional eating, and uncontrolled eating could influence an individual's ability to successfully regulate their energy intake post-surgery [9]. High levels of pre-surgical emotional eating were associated with poor weight loss 1 year after surgery [10], and a higher score on emotional eating in women suffering from obesity who underwent a gastric bypass was associated with an insufficient weight loss 2 years after surgery [11]. It was also suggested, using the Three- 
Factor Eating Questionnaire (TFEQ), that a higher vulnerability to various internal and external eating cues shortly after surgery was the main predictor of less successful short- and long-term weight loss [8]. Moreover, as suggested in the systematic review by Athanasiadis et al. (2021), emotional eating, food urges, binge eating, and loss of control/disinhibition when eating have been positively associated with weight regain after Roux-en-Y gastric bypass and sleeve gastrectomy [12].

In a clinical context, among various questionnaires, such as the TFEQ, the Dutch Eating Behavior Questionnaire (DEBQ) has been largely used to assess eating styles [13]. This questionnaire arises from the psychosomatic, the externality, and the restraint theories related to three kinds of eating styles: Emotional Eating (EmoE), External Eating (ExtE), and Restraint Eating (RE) [14]. In EmoE, eating occurs as a response to negative emotions, such as depression, anxiety, anger, sadness, and discouragement [15]. ExtE refers to the tendency to eat in response to positive external cues, such as the sight or the smell of food, regardless of internal signals of hunger and satiety [14]. RE implies making efforts to develop and maintain strategies to control calorie intake in order to obtain weight loss [16]. Multiple factors have been shown to contribute to those eating behavior styles. In females with morbid obesity, EmoE has been associated with a higher degree of negative affects, more difficulty in identifying feelings [17], neuroticism (which characterizes individuals who experience feelings such as anxiety, anger, guilt, and depression) [18,19], and poor interoceptive awareness, alexithymia, or poor emotion regulation strategies $[15,20]$. ExtE has been associated with neuroticism even if this relation is weaker than for EmoE [18]. RE seems to be influenced by sex (more frequent in females) [21], as well as by conscientiousness and neuroticism [22]. Furthermore, among bariatric surgery candidates, positive correlations have been reported between the severity of depression and both EmoE and ExtE; while a negative correlation has been shown between severity of depression and RE [23].

Impulsivity, a complex and multifaceted construct [24], is also important to consider. Authors have reported that EmoE, ExtE, and RE are associated with increased impulsivity in overweight and individuals suffering from obesity [18], even if such an association seems to be limited to responsiveness to rewards and reduced response inhibition [25]. Moreover, impulsivity may be associated with less weight loss after surgery, even if it is argued that it may be specific to state impulsivity [26]. As the direct effect of trait impulsivity on weight loss is not confirmed, this might be due to an indirect effect through eating behaviors.

Based on these previous theoretical considerations and empirical results, the aim of our work was to assess if depression, anxiety, and impulsivity traits represent important contributors to eating behaviors styles in patients suffering from obesity and seeking bariatric surgery. We expected to find strong links between depression, anxiety, and EmoE or ExtE. We also expected to find a relationship between impulsivity and EmoE or ExtE, given their strong co-occurrence [27]. For RE, expectations are more uncertain given the findings noted above.

\section{Materials And Methods}

\section{Participants}

A sample of 127 patients, all candidates for bariatric surgery, were recruited in a ward specialized in severe obesity in Reims (France). The participants were told that the study would enable a better understanding of the difficulties encountered by bariatric surgery candidates, and that there was no financial compensation. Although the study was proposed before the approval process for the surgery, they were also told that their results would not impact their treatment and the selection process. The inclusion criteria were obesity grade 2 (BMI $35.0-39.9 \mathrm{~kg} / \mathrm{m}^{2}$ ) plus at least one obesity-related comorbidity or obesity grade 3 (BMI $\geq 40.0$ $\mathrm{kg} / \mathrm{m}^{2}$ ), and all bariatric surgery candidates were without anorexia nervosa, bulimia or binge-eating disorder as assessed by a structured interview. Patients had to be French-speaking and to be 18 to 65 years old. As impulsivity is a construct affected by addiction, participants with present or past drug or alcohol abuse or dependence were not included. All study procedures were reviewed and approved by the local Institutional Review Board (Dossier IRB 2016-12). The study was carried out according to the Helsinki Declaration [28], and every patient included in the study provided written informed consent.

\section{Assessments}

For all participants, we assessed sex, age, and BMI ( $\mathrm{kg} / \mathrm{m}^{2}$; calculated from the measured weight and height). We used the Mini International Neuropsychiatric Interview (a structured interview) (French Version 5.0.0) (MINI) to investigate past and current 
psychiatric disorders, including alcohol abuse and dependence, drug abuse and dependence or anxiety disorders. The MINI contains 130 questions and screens 16 axis I DSM-IV disorders and one personality disorder (i.e., antisocial personality disorder).

Depression severity and anxiety

The severity of depression was assessed using the short version of the Beck Depression Inventory, which is a widely used self-report scale (BDI-13) $[29,30]$. The total score is obtained by adding the scores of 13 items and ranges from 0 to 39 , with higher scores indicating greater depressive symptoms. Cronbach's alpha was 0.837. Anxiety was evaluated with the State-Trait Anxiety Inventory (STAI), a self-report scale [31]. Trait anxiety refers to how dispositionally anxious a person is across time and situations; state anxiety refers to how anxious a person is feeling at a particular moment. This inventory is a 40 -item scale (20 items evaluate trait anxiety, and 20 items evaluate state anxiety), using a 4-point Likert scale for each item. The Cronbach's alpha value was 0.945 for the state scale and 0.933 for the trait scale.

Eating behaviors styles

The Dutch Eating Behavior Questionnaire (DEBQ), a self-report scale, was administered to assess Emotional, External, and Restraint Eating $[13,32]$. The DEBQ consists of 33 items answered on a 5-point Likert scale (ranging from "never" to "very often"). Thirteen items evaluate Emotional Eating, and ten items evaluate External Eating and Restraint Eating. The Cronbach's alpha values were 0.959 for EmoE, 0.748 for ExtE, and 0.855 for RE.

Impulsivity

We used the UPPS-P Impulsive Behavior Scale [33] to assess the facets of impulsivity, i.e., Negative Urgency, Positive Urgency, (lack of) Premeditation, (lack of) Perseverance, and Sensation Seeking. This shortened version (20 items) has 4 items per scale, and each item is responded to on a 4-point Likert-type scale. This self-report scale has received endorsement from the National Institutes of Health's (NIH) PhenX Toolkit as the recommended self-report measure of impulsigenic traits [34]. The Cronbach's alpha values in our sample were $0.796,0.703,0.754,0.738$, and 0.623 , respectively.

\section{Data analytic plan}

All variables were screened for extreme outliers using box plot analyses. Descriptive (degree of skewness and kurtosis) and graphical methods were used to examine whether data were normally distributed. The relationships between the eating style scores, clinical characteristics, and impulsivity dimensions were examined using Pearson's correlation, and separate hierarchical multiple regressions were performed to determine which variables predicted each of the eating behaviors styles as measured by the DEBQ subscales. All variables were considered clinically relevant and selected for all regression models. We constructed three blocks: 1) demographic information (i.e., age, sex), 2) affective symptoms (i.e., anxiety and depression), and 3) impulsivity dimensions (i.e., UPPS-P). Because DEBQ scores are known to be influenced by age and sex, these variables were forced as covariates in the first step. Then, anxiety (trait and state scores) and depression severity were entered in the second step, and all the impulsivity scores were entered in the third step. A forward selection was performed in steps 2 and 3. To test for multicollinearity, we examined the variance inflation factor (VIF) and the tolerance values (1/VIF). The tolerance ranged from 0.819 to 0.957 , indicating that there was no issue [35]. All the statistical analyses were performed with SPSS ${ }^{8}$ software, version 24.0 (SPSS, Inc., Chicago, IL, USA) and pvalues $<0.05$ were regarded as statistically significant.

\section{Results}

\section{Descriptive data}

Most participants were female $(\mathrm{N}=88,69.29 \%)$ and ranged from 20 to 61 years old, with a mean age of $41.27 \pm 11.20$ years old (females $39.19 \pm 11.12$ years old ; males $45.95 \pm 10.01$ years old). The mean BMI was $45.65 \pm 6.72 \mathrm{~kg} / \mathrm{m}^{2}$ (females $45.85 \pm 6.86$ $\mathrm{kg} / \mathrm{m}^{2}$; males $45.22 \pm 6.47 \mathrm{~kg} / \mathrm{m}^{2}$ ). Twenty-nine participants were obesity grade 2 (19 females) and 98 obesity grade 3 (69 females).

According to psychiatric diagnoses, 5.5\% presented a current major depressive disorder, $23.6 \%$ presented a past major depressive disorder, $7.9 \%$ presented current dysthymia, $4.7 \%$ presented a suicidal risk, $0.8 \%$ presented a past hypomanic episode, 
$1.6 \%$ presented a current panic disorder, $13.4 \%$ presented current agoraphobia, $7.1 \%$ presented a current social phobia, $0.8 \%$ presented a current obsessive and compulsive disorder, $0.8 \%$ presented a current post-traumatic stress disorder, and $7.9 \%$ presented a current generalized anxiety disorder.

Eating behaviors styles, depression, anxiety, and impulsivity scores are shown in Table 1 for the overall population and according to sex.

\section{Bivariate correlations}

Among the eating styles scores, EmoE was significantly correlated with ExtE, depression and anxiety scores, and all dimensions of impulsivity (Table 2). ExtE was significantly correlated with EmoE, depression and anxiety scores, positive urgency, lack of perseverance, and sensation seeking. RE was not correlated with any variable (Table 2). The male participants were older than the females, and the females presented more emotional eating than the males (Table 2).

\section{Relative contributions of depression, anxiety, and impulsiveness variables to eating behaviors styles scores}

The first regression analysis, with EmoE as the dependent variable, showed a significant model in all three steps $(F(2,124)=6.34, p$ $=0.002$ in step 1 , including sex and age; $F(3,123)=12.17, p<0.001$ in step 2, including symptoms of anxiety trait; and $F(4,122)=$ $11.54, p<0.001$ in step 3 , including UPPS lack of perseverance). R square change was $9.3 \%$ in the first step $(p=0.002), 13.6 \%$ in the second step $(p<0.001)$, and $4.6 \%$ in the third step $(p=0.006)$ (Table 3$)$.

The second regression analysis, with ExtE as the dependent variable, showed a significant model in the two last steps $(F(2,124)=$ $0.984, p=0.377$ in step 1 , including sex and age; $F(3,123)=3.573, p=0.016$ in step 2 , including depression severity score; and $F$ $(4,122)=3.746, p=0.007$ in step 3 , including UPPS positive urgency). $R$ square change was $1.6 \%$ in the first step $(p=0.377), 6.5 \%$ in step $2(p=0.004)$, and $2.9 \%$ in the third step $(p=0.048)$ (Table 3$)$.

The third regression analysis, with RE as the dependent variable, showed a non-significant model $(F(2,124)=0.172, p=0.842)$. No variable contributed significantly to the prediction of $\mathrm{RE}$.

\section{Discussion}

The current study aimed to examine the potential contributions of depression, anxiety, and the different facets of impulsivity, as defined by the UPPS-P model, to each of the three eating behaviors styles assessed by the DEBQ (i.e., EmoE, ExtE, and RE) in patients suffering from obesity and presenting for bariatric surgery.

Concerning EmoE, according to our main hypothesis, we found significant and positive correlations between this eating behavior style and depression level, anxiety levels, and all dimensions of impulsivity. Females presented more EmoE than males. Furthermore, linear regression analysis showed that sex (female), trait anxiety, and lack of perseverance were related to EmoE. These results show that females are at a higher risk than males for developing EmoE. This finding is consistent with the findings of Gade et al. (2014) among patients suffering from obesity before gastric bypass surgery. Trait anxiety appears as an explanatory factor for EmoE. The variety of affects that may take place in EmoE is a topic recently open to debate [36], and each type of affect, including positive affects, could determine a different subcategory of EmoE. However, EmoE due to anxiety symptoms has been demonstrated as less associated with psychopathological phenomena than those due to depression [36]. Thus, the emotional dysregulation known to occur in depression and not negative affects by themselves might be considered as the drivers of EmoE [36,37]. Lack of perseverance was the only facet of impulsivity found as an explanatory factor in EmoE (also confirmed by cross-validation of our regression model). This dimension of impulsivity is defined as the difficulty in staying focused on a task because of the intrusion into the memory of thoughts and memories previously useful but irrelevant to the current task [38-40]. It has been linked to executive and decision-making functions [41]. Hence, one of the mechanisms of EmoE would be the existence of intrusive thoughts, although our study does not allow us to determine whether the topic of these thoughts are food, weight, body dissatisfaction, or manifestations of post-traumatic stress disorder, as has been observed in patients suffering from bulimia or among bariatric surgery candidates [42-45]. The fact that lack of perseverance was identified as an explanatory factor for EmoE raises the question of the link between emotions, intrusive thoughts, and food. Canale et al. (2017) have proposed a disruptive role of emotions on the resistance to proactive interference process [46]. Thus, intense emotions would lead to strong intrusive thoughts 
and then food intake to try to cope with these. This hypothesis is supported by the existence of increased activity in the orbitofrontal cortex in participants who have received a negative mood induction and have been exposed to images of appetizing foods, reflecting a rise in the value of reward food cues in case of negative affects [47]. The intervention of the reward system further raises the question of potential addictive mechanisms in EmoE. Since the lack of perseverance has been linked to craving $[48,49]$, these difficulties in overcoming proactive interference may reflect difficulties in managing obsessions for food in connection with a "craving" in EmoE [50]. In summary, this brings to the fore the importance of intrusive thoughts in EmoE and suggests that the lack of inhibition of mental images/thoughts could be responsible for a loss of control of food intake. Eating would thus be an ineffective and inappropriate means to cope with emotions, which, by force of repetition and mental elaboration, could be automatized and self-sustained.

The secondary objective of our study was to investigate the potential links between depression, anxiety, impulsivity, and ExtE. This eating behavior style remains associated with unhealthy food intake [18,51,52] and a serious increase in BMI [21,53], even if it is to a lesser extent than EmoE. In our study, depression and anxiety scores were significantly correlated to ExtE. For impulsivity, our results were like those of previous researches $[18,51,54,55]$, i.e., a significant and positive correlation between ExtE and urgency and lack of perseverance. In addition, we found an association with the sensation-seeking dimension. Regression analysis adjusted for sex and age showed that depression severity and positive urgency predicted ExtE. Sevinçer et al. (2017) suggested a positive correlation between the severity of depression and ExtE among bariatric surgery candidates [23]. In a population of adults from the community, general practice, and specialized mental health care, Paans and colleagues (2019) found that depression and unhealthy eating styles contributed independently to poorer dietary quality and higher intake of sweet foods and fast-food/savory snacks [56]. These authors also found that the association between depression and higher intake of snack/fast-food was explained by ExtE, suggesting that ExtE cues may be an important mechanism linking depression and obesity. Positive urgency, the tendency to act rashly in response to positive emotions, appears to be less relevant for dysregulated eating [57]. Using the Barratt Impulsiveness Scale [58], Meule and Platte (2015) showed that ExtE acts as a mediator between motor impulsivity and food overconsumption [59]. Kakoschke et al. (2015) showed that motor impulsivity and attentional impulsivity interact and are mutually reinforced in ExtE, while attentional impulsivity moderates the effect of motor impulsivity on food intake [51]. The combination of these two impulsivity dimensions would be required for the development of overeating and overweight, possibly indicating specific cognitive mechanisms in the food domain [60]. Such potentiating effects could explain why results regarding ExtE and its role in obesity are still sometimes contradictory.

Regarding RE, no association was found with any of the dimensions of impulsivity, nor depression and anxiety. Available data on the subject are still heterogeneous $[18,25,61]$ and remain to be qualified. However, using TFEQ, Hindle et al. $(2020)$ showed that patients with higher cognitive restriction before surgery perceived less reduction in hunger after surgery; this eating behavior style thus requires further studies addressing its correlates [62]. Given differences between the scales used to identify RE, several types of restrictive eating behaviors could be distinguished, corresponding to different personality profiles, different impulsivity traits, and different levels of success in terms of weight loss [25]. In DEBQ, RE corresponds to the existence of behavioral strategies used to control energy inputs, followed by success or not $[13,63]$. RE might thus include a broad range of individual profiles.

This might explain why results are mixed in the literature and why our study does not find a correlation with the explored dimensions of impulsivity. More generally, based on our results, we can assume that food restriction alone, and as defined by the DEBQ, does not necessarily mean a high level of impulsivity and high likelihood of weight regain, as long as some personality traits are not associated with. On the other hand, our study population is likely to display a particular type of DEBQ-RE: their restriction goals were a priori defeated. Moreover, the evaluation mode (by self-reports) is a potential source of response bias (self-complacency or selfhandicap bias) because individuals may believe that they have interest in indicating that they have no more implemented restriction strategies even if some of them might present a restraint eating style (implying that these alone have not been enough, and that surgery is therefore necessary). The exclusion of individuals with eating disorders from our study population may also explain conflicting findings compared to other studies.

This study has several limitations. The first is that the population was limited to only candidates for bariatric surgery, which limits the generalizability of the findings. For instance, moderate obesity was not present in the current sample, in addition to other exclusion criteria, including anorexia, bulimia, binge-eating disorder, and an addiction to a psychoactive substance. Our sample is, therefore, only representative of this specific situation. However, there may be an advantage in having targeted this population because eating disorders are themselves very strongly associated with impulsivity, with heterogeneous results according to their 
type. Because explanatory models are probably very different based on the presence of an eating disorder or not, our results make it possible to study - in a more specific way - the mechanisms of each eating behavior style in individuals without eating disorders. Our study also makes it possible to focus on people seeking bariatric surgery, to adapt their care, and so, to minimize the risk of relapse. Future studies could be conducted to investigate the effect of focused therapies on relapse in these patients. A second limitation comes from the unbalanced sex ratio: $69.3 \%$ of participants are female. And lastly, we assessed depression, anxiety, impulsivity, and eating behaviors styles through self-reports, which are subjects to possible bias. However, the validity of these questionnaires has been well supported in previous studies, and our reliability indices were satisfactory.

In conclusion, the results of this study suggest that in individuals suffering from obesity and seeking bariatric surgery, trait anxiety and a lack of resistance to proactive interference signal risk of EmoE, while depression severity and the tendency to act rashly in response to positive emotions signal risk of ExtE. Therapies targeting abilities to regulate negative affects and impulsivity look promising and require further studies.

\section{Abbreviations}

BDI: Beck Depression Inventory

BMI: body mass index

DEBQ: Dutch Eating Behavior Questionnaire

EmoE: Emotional Eating

ExtE: External Eating

MINI: Mini International Neuropsychiatric Interview

RE: Restraint Eating

STAI: State-Trait Anxiety Inventory

STAI-A: State-Trait Anxiety Inventory (State)

STAI-B: State-Trait Anxiety Inventory (Trait)

TFEQ: Three-Factor Eating Questionnaire

UPPS: UPPS Impulsive Behavior Scale

\section{Declarations}

\section{Ethics approval and consent to participate}

All study procedures were reviewed and approved by the local Institutional Review Board (Dossier IRB 2016-12). The study was carried out according to the Helsinki Declaration, and every patient included in the study provided written informed consent.

\section{Consent for publication}

Not applicable

\section{Availability of data and materials}

The qualitative datasets (i.e., transcripts, coding, and themes) used and/or analyzed during the current study are available from the corresponding author upon reasonable request.

\section{Competing interests}


The authors declare no conflict of interest.

\section{Funding}

This research received no external funding.

\section{Authors' Contributions}

Conceptualization, Farid Benzerouk; Formal analysis, Farid Benzerouk and Fabien Gierski; Investigation, Farid Benzerouk and Sarah Barrière; Methodology, Fabien Gierski; Supervision, Fabien Gierski and Arthur Kaladjian; Validation, Farid Benzerouk, Monique Guénin, Fabien Gierski, Delphine Raucher-Chéné, Sarah Barrière, Eric Bertin and Arthur Kaladjian; Writing - original draft, Farid Benzerouk; Writing - review \& editing, Farid Benzerouk.

\section{Acknowledgments}

The authors thank the volunteers who made the study possible through their participation and collaboration.

\section{References}

[1] WHO | Obesity. WHO n.d. https://www.who.int/topics/obesity/en/ (accessed March 22, 2020).

[2] Colquitt JL, Pickett K, Loveman E, Frampton GK. Surgery for weight loss in adults. Cochrane Database Syst Rev 2014:CD003641. https://doi.org/10.1002/14651858.CD003641.pub4.

[3] Carlsson LMS, Peltonen M, Ahlin S, Anveden Å, Bouchard C, Carlsson B, et al. Bariatric surgery and prevention of type 2 diabetes in Swedish obese subjects. N Engl J Med 2012;367:695-704. https://doi.org/10.1056/NEJMoa1112082.

[4] Peterli R, Wölnerhanssen BK, Peters T, Vetter D, Kröll D, Borbély Y, et al. Effect of laparoscopic sleeve gastrectomy vs laparoscopic roux-en-y gastric bypass on weight loss in patients with morbid obesity: The SM-BOSS Randomized Clinical Trial. JAMA 2018;319:255-65. https://doi.org/10.1001/jama.2017.20897.

[5] Sjöström L, Lindroos A-K, Peltonen M, Torgerson J, Bouchard C, Carlsson B, et al. Lifestyle, diabetes, and cardiovascular risk factors 10 years after bariatric surgery. N Engl J Med 2004;351:2683-93. https://doi.org/10.1056/NEJMoa035622.

[6] Sjöström L, Peltonen M, Jacobson P, Sjöström CD, Karason K, Wedel H, et al. Bariatric surgery and long-term cardiovascular events. JAMA 2012;307:56-65. https://doi.org/10.1001/jama.2011.1914.

[7] Sarwer DB, Wadden TA, Ashare RL, Spitzer JC, McCuen-Wurst C, LaGrotte C, et al. Psychopathology, disordered eating, and impulsivity in patients seeking bariatric surgery. Surg Obes Relat Dis 2021;17:516-24. https://doi.org/10.1016/j.soard.2020.11.005.

[8] Konttinen H, Peltonen M, Sjöström L, Carlsson L, Karlsson J. Psychological aspects of eating behavior as predictors of 10-y weight changes after surgical and conventional treatment of severe obesity: results from the Swedish Obese Subjects intervention study. Am J Clin Nutr 2015;101:16-24. https://doi.org/10.3945/ajcn.114.095182.

[9] Bryant EJ, Malik MS, Whitford-Bartle T, Waters GM. The effects of bariatric surgery on psychological aspects of eating behaviour and food intake in humans. Appetite 2020;150:104575. https://doi.org/10.1016/j.appet.2019.104575.

[10] Miller-Matero LR, Bryce K, Saulino CK, Dykhuis KE, Genaw J, Carlin AM. Problematic eating behaviors predict outcomes after bariatric surgery. Obes Surg 2018;28:1910-5. https://doi.org/10.1007/s11695-018-3124-0.

[11] Novelli IR, Fonseca LG, Gomes DL, Dutra ES, Baiocchi de Carvalho KM. Emotional eating behavior hinders body weight loss in women after Roux-en-Y gastric bypass surgery. Nutrition 2018;49:13-6. https://doi.org/10.1016/j.nut.2017.11.017.

[12] Athanasiadis DI, Martin A, Kapsampelis P, Monfared S, Stefanidis D. Factors associated with weight regain post-bariatric surgery: A systematic review. Surg Endosc 2021. https://doi.org/10.1007/s00464-021-08329-w. 
[13] Strien T van, Frijters JER, Bergers GPA, Defares PB. The Dutch eating behavior questionnaire (DEBQ) for assessment of restrained, emotional and external eating behavior. International Journal Eating Disorders 1986;5:295-315.

[14] Canetti L, Bachar E, Berry EM. Food and emotion. Behav Processes 2002;60:157-64. https://doi.org/10.1016/s03766357(02)00082-7.

[15] van Strien T. Causes of emotional eating and matched treatment of obesity. Curr Diab Rep 2018;18:35.

https://doi.org/10.1007/s11892-018-1000-x.

[16] Nurkkala M, Kaikkonen K, Vanhala ML, Karhunen L, Keränen A-M, Korpelainen R. Lifestyle intervention has a beneficial effect on eating behavior and long-term weight loss in obese adults. Eat Behav 2015;18:179-85.

https://doi.org/10.1016/j.eatbeh.2015.05.009.

[17] Zijlstra H, van Middendorp H, Devaere L, Larsen JK, van Ramshorst B, Geenen R. Emotion processing and regulation in women with morbid obesity who apply for bariatric surgery. Psychology \& Health 2012;27:1375-87.

https://doi.org/10.1080/08870446.2011.600761.

[18] Elfhag K, Morey LC. Personality traits and eating behavior in the obese: Poor self-control in emotional and external eating but personality assets in restrained eating. Eat Behav 2008;9:285-93. https://doi.org/10.1016/j.eatbeh.2007.10.003.

[19] Heaven PC, Mulligan K, Merrilees R, Woods T, Fairooz Y. Neuroticism and conscientiousness as predictors of emotional, external, and restrained eating behaviors. Int J Eat Disord 2001;30:161-6. https://doi.org/10.1002/eat.1068.

[20] Snoek HM, Engels RCME, Janssens JMAM, van Strien T. Parental behaviour and adolescents' emotional eating. Appetite 2007;49:223-30. https://doi.org/10.1016/j.appet.2007.02.004.

[21] Burton P, Smit HJ, Lightowler HJ. The influence of restrained and external eating patterns on overeating. Appetite 2007;49:191-7. https://doi.org/10.1016/j.appet.2007.01.007.

[22] Gade H, Rosenvinge JH, Hjelmesæth J, Friborg O. Psychological correlates to dysfunctional eating patterns among morbidly obese patients accepted for bariatric surgery. OFA 2014;7:111-9. https://doi.org/10.1159/000362257.

[23] Sevinçer GM, Konuk N, Ipekçioğlu D, Crosby RD, Cao L, Coskun H, et al. Association between depression and eating behaviors among bariatric surgery candidates in a Turkish sample. Eat Weight Disord 2017;22:117-23. https://doi.org/10.1007/s40519-0160296-2.

[24] Sharma L, Kohl K, Morgan TA, Clark LA. "Impulsivity": Relations between self-report and behavior. Journal of Personality and Social Psychology 2013;104:559-75. https://doi.org/10.1037/a0031181.

[25] Mills JS, Weinheimer L, Polivy J, Herman CP. Are there different types of dieters? A review of personality and dietary restraint. Appetite 2018;125:380-400. https://doi.org/10.1016/j.appet.2018.02.014.

[26] Yeo D, Toh A, Yeo C, Low G, Yeo JZ, Aung MO, et al. The impact of impulsivity on weight loss after bariatric surgery: a systematic review. Eat Weight Disord 2021;26:425-38. https://doi.org/10.1007/s40519-020-00890-y.

[27] Heatherton TF, Baumeister RF. Binge eating as escape from self-awareness. Psychol Bull 1991;110:86-108.

https://doi.org/10.1037/0033-2909.110.1.86.

[28] World Medical Association Declaration of Helsinki: Ethical Principles for Medical Research Involving Human Subjects. JAMA 2013;310:2191. https://doi.org/10.1001/jama.2013.281053.

[29] Beck AT, Steer RA, Carbin MG. Psychometric properties of the Beck Depression Inventory: Twenty-five years of evaluation. Clinical Psychology Review 1988;8:77-100. https://doi.org/10.1016/0272-7358(88)90050-5.

[30] Collet L, Cottraux J. [The shortened Beck depression inventory (13 items). Study of the concurrent validity with the Hamilton scale and Widlöcher's retardation scale]. Encephale 1986;12:77-9. 
[31] Spielberger CD, Gorsuch RL, Lushene RE. Manual for the State-Trait Anxiety Inventory 1970.

[32] Lluch A, Kahn J, Stricker-Krongrad A, Ziegler O, Drouin P, Méjean L. Internal validation of a French version of the Dutch eating behaviour questionnaire. Eur Psychiatry 1996;11:198-203. https://doi.org/10.1016/0924-9338(96)88391-X.

[33] Billieux J, Rochat L, Ceschi G, Carré A, Offerlin-Meyer I, Defeldre A-C, et al. Validation of a short French version of the UPPS-P Impulsive Behavior Scale. Compr Psychiatry 2012;53:609-15. https://doi.org/10.1016/j.comppsych.2011.09.001.

[34] Hamilton CM, Strader LC, Pratt JG, Maiese D, Hendershot T, Kwok RK, et al. The PhenX Toolkit: Get the most from your measures. Am J Epidemiol 2011;174:253-60. https://doi.org/10.1093/aje/kwr193.

[35] Menard S. Logistic regression: From introductory to advanced concepts and applications. SAGE; 2010.

[36] Braden A, Musher-Eizenman D, Watford T, Emley E. Eating when depressed, anxious, bored, or happy: Are emotional eating types associated with unique psychological and physical health correlates? Appetite 2018;125:410-7.

https://doi.org/10.1016/j.appet.2018.02.022.

[37] Telch CF, Agras WS, Linehan MM. Dialectical behavior therapy for binge eating disorder. J Consult Clin Psychol 2001;69:1061-5. https://doi.org/10.1037//0022-006x.69.6.1061.

[38] Gay P. Impulsivité, contrôle de la pensée et inhibition 2009. https://doi.org/10.13097/archive-ouverte/unige:5153.

[39] Gay P, Rochat L, Billieux J, d'Acremont M, Van der Linden M. Heterogeneous inhibition processes involved in different facets of self-reported impulsivity: evidence from a community sample. Acta Psychol (Amst) 2008;129:332-9.

https://doi.org/10.1016/j.actpsy.2008.08.010.

[40] Philippe G, Courvoisier DS, Billieux J, Rochat L, Schmidt RE, Linden MV der. Can the distinction between intentional and unintentional interference control help differentiate varieties of impulsivity? Journal of Research in Personality 2010;44:46-52. https://doi.org/10.1016/j.jrp.2009.10.003.

[41] Van der Linden M, Billieux J. La contribution de la psychopathologie cognitive à l'intervention psychologique 2011.

[42] Hamburger WW. Emotional aspects of obesity. Obesity Research 1997;5:162-71. https://doi.org/10.1002/j.1550-

8528.1997.tb00658.x.

[43] Sunday SR, Halmi KA, Einhorn A. The Yale-Brown-Cornell Eating Disorder Scale: A new scale to assess eating disorder symptomatology. Int J Eat Disord 1995;18:237-45. https://doi.org/10.1002/1098-108x(199511)18:3<237::aideat2260180305>3.0.c0;2-1.

[44] Vanderlinden J, Grave RD, Fernandez F, Vandereycken W, Pieters G, Noorduin C. Which factors do provoke binge eating? An exploratory study in eating disorder patients. Eating and Weight Disorders - Studies on Anorexia, Bulimia and Obesity 2004;4:300-5. https://doi.org/10.1007/BF03325086.

[45] Geller S, Levy S, Goldzweig G, Hamdan S, Manor A, Dahan S, et al. Psychological distress among bariatric surgery candidates: The roles of body image and emotional eating. Clin Obes 2019;9:e12298. https://doi.org/10.1111/cob.12298.

[46] Canale N, Rubaltelli E, Vieno A, Pittarello A, Billieux J. Impulsivity influences betting under stress in laboratory gambling. Sci Rep 2017;7:10668. https://doi.org/10.1038/s41598-017-10745-9.

[47] Wagner DD, Boswell RG, Kelley WM, Heatherton TF. Inducing negative affect increases the reward value of appetizing foods in dieters. Journal of Cognitive Neuroscience 2012;24:1625-33. https://doi.org/10.1162/jocn_a_00238.

[48] Billieux J, Van der Linden M. Impulsivité et dépendances: une approche cognitive et motivationnelle à la lumière du modèle UPPS de Whiteside et Lynam. Revue Francophone de Clininque Comportementale et Cognitive 2008;13:12. 
[49] Mobbs 0 . Une approche cognitive des comportements alimentaires problématiques: le rôle de l'impulsivité, de l'inhibition, et des attitudes implicites. University of Geneva, 2011. https://doi.org/10.13097/archive-ouverte/unige:16070.

[50] Kavanagh DJ, Andrade J, May J. Imaginary Relish and Exquisite Torture: The elaborated intrusion theory of desire. Psychological Review 2005;112:446-67. https://doi.org/10.1037/0033-295X.112.2.446.

[51] Kakoschke N, Kemps E, Tiggemann M. External eating mediates the relationship between impulsivity and unhealthy food intake. Physiol Behav 2015;147:117-21. https://doi.org/10.1016/j.physbeh.2015.04.030.

[52] Nijs IMT, Muris P, Euser AS, Franken IHA. Differences in attention to food and food intake between overweight/obese and normal-weight females under conditions of hunger and satiety. Appetite 2010;54:243-54. https://doi.org/10.1016/j.appet.2009.11.004.

[53] Bongers P, van de Giessen E, Roefs A, Nederkoorn C, Booij J, van den Brink W, et al. Being impulsive and obese increases susceptibility to speeded detection of high-calorie foods. Health Psychology 2015;34:677-85. https://doi.org/10.1037/hea0000167.

[54] Ebneter D, Latner J, Rosewall J, Chisholm A. Impulsivity in restrained eaters: Emotional and external eating are associated with attentional and motor impulsivity. Eat Weight Disord 2012;17:e62-5. https://doi.org/10.1007/BF03325330.

[55] Ouwens MA, van Strien T, van Leeuwe JFJ. Possible pathways between depression, emotional and external eating. A structural equation model. Appetite 2009;53:245-8. https://doi.org/10.1016/j.appet.2009.06.001.

[56] Paans NPG, Gibson-Smith D, Bot M, van Strien T, Brouwer IA, Visser M, et al. Depression and eating styles are independently associated with dietary intake. Appetite 2019;134:103-10. https://doi.org/10.1016/j.appet.2018.12.030.

[57] Gruber J. The Oxford Handbook of Positive Emotion and Psychopathology. Oxford, New York: Oxford University Press; 2019.

[58] Patton JH, Stanford MS, Barratt ES. Factor structure of the Barratt impulsiveness scale. J Clin Psychol 1995;51:768-74. https://doi.org/10.1002/1097-4679(199511)51:6<768::aid-jclp2270510607>3.0.co;2-1.

[59] Meule A, Platte P. Facets of impulsivity interactively predict body fat and binge eating in young women. Appetite 2015;87:3527. https://doi.org/10.1016/j.appet.2015.01.003.

[60] Schmitz F, Naumann E, Trentowska M, Svaldi J. Attentional bias for food cues in binge eating disorder. Appetite 2014;80:7080. https://doi.org/10.1016/j.appet.2014.04.023.

[61] Hou R, Mogg K, Bradley BP, Moss-Morris R, Peveler R, Roefs A. External eating, impulsivity and attentional bias to food cues. Appetite 2011;56:424-7. https://doi.org/10.1016/j.appet.2011.01.019.

[62] Hindle A, De la Piedad Garcia X, Hayden M, O’Brien PE, Brennan L. Pre-operative restraint and post-operative hunger, disinhibition and emotional eating predict weight loss at 2 years post-laparoscopic adjustable gastric banding. Obes Surg 2020;30:1347-59. https://doi.org/10.1007/s11695-019-04274-9.

[63] Cebolla A, Barrada JR, van Strien T, Oliver E, Baños R. Validation of the Dutch Eating Behavior Questionnaire (DEBQ) in a sample of Spanish women. Appetite 2014;73:58-64. https://doi.org/10.1016/j.appet.2013.10.014.

[64] Marek RJ, Tarescavage AM, Ben-Porath YS, Ashton K, Merrell Rish J, Heinberg LJ. Using pre-surgical psychological testing to predict 1-year appointment adherence and weight loss in bariatric surgery patients: predictive validity and methodological considerations. Surg Obes Relat Dis 2015;11:1171-81. https://doi.org/10.1016/j.soard.2015.03.020.

\section{Tables}

Table 1. Descriptive data for eating behaviors styles, depression, anxiety, and impulsivity scores in the overall population, in females, and in males. 


\begin{tabular}{|c|c|c|c|c|c|c|}
\hline & \multicolumn{2}{|c|}{ Overall population $(\mathrm{N}=127)$} & \multicolumn{2}{|l|}{ Females $(\mathrm{N}=88)$} & \multicolumn{2}{|l|}{ Males $(\mathrm{N}=39)$} \\
\hline & Mean (Min-Max) & SD & Mean (Min-Max) & SD & Mean (Min-Max) & SD \\
\hline Emotional Eating & $2.38(0.85-5.00)$ & 1.04 & $2.59(0.85-5.00)$ & 1.06 & $1.91(0.92-3.69)$ & .85 \\
\hline External Eating & $2.57(1.10-4.20)$ & .62 & $2.57(1.10-4.20)$ & .59 & $2.56(1.20-3.90)$ & .70 \\
\hline Restraint Eating & $2.77(1.00-4.60)$ & .77 & $2.78(1.30-4.60)$ & .78 & $2.74(1.00-4.60)$ & .76 \\
\hline $\mathrm{BDI}^{1}$ & $9.55(0-31)$ & 6.52 & $10.26(0-27)$ & 6.70 & $7.95(0-31)$ & 5.87 \\
\hline STAI-A ${ }^{2}$ & $33.76(20-76)$ & 12.08 & $33.82(20-76)$ & 12.00 & $33.64(20-71)$ & 12.40 \\
\hline STAI-B ${ }^{3}$ & $37.99(20-70)$ & 11.76 & $30.09(20-70)$ & 11.96 & $35.51(20-70)$ & 11.05 \\
\hline UPPS Negative Urgency ${ }^{4}$ & $8.53(4-15)$ & 2.94 & $8.56(4-15)$ & 2.94 & $8.46(4-15)$ & 2.98 \\
\hline UPPS Positive Urgency ${ }^{4}$ & $9.46(4-16)$ & 2.45 & $9.57(5-15)$ & 2.37 & $9.21(4-16)$ & 2.64 \\
\hline UPPS Lack of premeditation 4 & $6.62(4-11)$ & 2.04 & $6.69(4-11)$ & 2.12 & $6.46(4-10)$ & 1.88 \\
\hline UPPS Lack of perseverance 4 & $6.06(4-13)$ & 2.07 & $6.28(4-13)$ & 2.16 & $5.56(4-9)$ & 1.77 \\
\hline UPPS Sensation seeking ${ }^{4}$ & $8.49(4-15)$ & 2.37 & $8.49(4-14)$ & 2.34 & $8.49(4-15)$ & 2.66 \\
\hline
\end{tabular}

Note: ${ }^{1} \mathrm{BDI}=$ Beck Depression Inventory, ${ }^{2} \mathrm{STAl}-\mathrm{A}=$ State-Trait Anxiety Inventory (State), ${ }^{3} \mathrm{STAl}-\mathrm{B}=$ State-Trait Anxiety Inventory (Trait), ${ }^{4}$ UPPS = UPPS-P Impulsive Behavior Scale. Min = Minimum, Max = Maximum.

Table 2. Bivariate correlations made in the whole sample between eating behaviors styles scores, clinical characteristics, and impulsivity dimensions scores. 


\begin{tabular}{|c|c|c|c|c|c|c|c|c|c|c|c|c|}
\hline & 1 & 2 & 3 & 4 & 5 & 6 & 7 & 8 & 9 & 10 & 11 & 12 \\
\hline $\begin{array}{l}\text { 1. Emotional } \\
\text { Eating }\end{array}$ & - & - & - & - & - & - & - & - & - & - & - & \\
\hline $\begin{array}{l}\text { 2. External } \\
\text { Eating }\end{array}$ & $.554^{\star \star}$ & - & - & - & - & - & - & - & - & - & - & \\
\hline $\begin{array}{l}\text { 3. Restraint } \\
\text { Eating }\end{array}$ & -.002 & -.121 & - & - & - & - & - & - & - & - & - & \\
\hline 4. Age & -.103 & -.121 & .038 & - & - & - & - & - & - & - & - & \\
\hline 5. $\mathrm{BDI}^{[1]}$ & $.401^{\star *}$ & $.272^{\star \star}$ & .026 & $.258 * \star$ & - & - & - & - & - & - & - & \\
\hline 6. STAI-A ${ }^{[2]}$ & $.364^{\star \star}$ & $.206 *$ & .049 & $-.194^{\star}$ & $.664^{\star \star}$ & - & - & - & - & - & - & \\
\hline 7. STAI-B ${ }^{[3]}$ & $.407^{\star \star}$ & $.248 * \star$ & -.049 & $-.185^{\star}$ & $.743^{* *}$ & $.790 * \star$ & - & - & - & - & - & \\
\hline $\begin{array}{l}\text { 8. UPPS-P } \\
\text { Negative } \\
\text { Urgency }^{[4]}\end{array}$ & $.256 * \star$ & .146 & .015 & .041 & $.418^{\star *}$ & .468 ** & $.517^{\star \star}$ & - & - & - & - & \\
\hline $\begin{array}{l}\text { 9. UPPS-P } \\
\text { Positive } \\
\text { Urgency } 4\end{array}$ & $.201 *$ & $.219 *$ & .013 & .031 & $.227 *$ & .163 & $.229 * *$ & .650 ** & - & - & - & \\
\hline $\begin{array}{l}\text { 10. UPPS-P } \\
\text { Lack of } \\
\text { premeditation }{ }^{4}\end{array}$ & $.200 *$ & .088 & -.117 & .052 & $.207 *$ & $.288 * \star$ & $.349 * *$ & $.299 * \star$ & .162 & - & - & \\
\hline $\begin{array}{l}\text { 11. UPPS-P } \\
\text { Lack of } \\
\text { perseverance }{ }^{4}\end{array}$ & $.382^{\star \star}$ & $.220 *$ & .005 & -.042 & $.334^{\star *}$ & $.320 \star \star$ & $.389 * *$ & $.252^{\star \star}$ & $.232^{\star \star}$ & $.495^{\star \star}$ & - & \\
\hline $\begin{array}{l}\text { 12. UPPS-P } \\
\text { Sensation } \\
\text { seeking }\end{array}$ & $.204^{*}$ & $.236 * \star$ & .008 & -.004 & $.306 * \star$ & $.259 \star \star$ & $.255^{\star \star}$ & .451 ** & $.567^{\star \star}$ & .078 & .134 & \\
\hline 13 Gender $^{5}$ & $-.304 * \star$ & -.004 & -.025 & $.279 * *$ & -.164 & -.007 & -.141 & -.015 & -.069 & -.053 & -.161 & .000 \\
\hline
\end{tabular}

Note: ${ }^{1} \mathrm{BDI}=$ Beck Depression Inventory, ${ }^{2} \mathrm{STAI}-\mathrm{A}=$ State-Trait Anxiety Inventory (State), ${ }^{3} \mathrm{STAI}-\mathrm{B}=$ State-Trait Anxiety Inventory (Trait), ${ }^{4}$ UPPS-P = UPPS-P Impulsive Behavior Scale, ${ }^{5}$ Sex (0: females; 1 : males). ${ }^{*} p<0.05 ;{ }^{* *} p<0.01$.

Table 3 Hierarchical linear regressions of anxiety, depression severity, and impulsivity traits in relation to eating behaviors styles in the whole sample. This table depicts results from significant final steps of regression analyses (i.e., for EmoE and ExtE). 


\begin{tabular}{|c|c|c|c|c|c|}
\hline & \multicolumn{3}{|c|}{ Emotional Eating } & \multicolumn{2}{|c|}{ External Eating } \\
\hline & \multicolumn{3}{|c|}{ Model: $R=.52$} & \multicolumn{2}{|c|}{ Model: $R=.33$} \\
\hline & \multicolumn{3}{|c|}{ Adjusted $R^{2}=.25$} & \multicolumn{2}{|c|}{ Adjusted $R^{2}=.08$} \\
\hline & Bêta & $p$ & & Bêta & $p$ \\
\hline Sex & -.233 & .005 & Sex & .069 & .440 \\
\hline Age & .026 & .755 & Age & -.089 & .334 \\
\hline STAI-B ${ }^{1}$ & .287 & .001 & $B D R$ & .221 & .017 \\
\hline UPPS & & & UPPS 3 & & \\
\hline Lack of perseverance & .234 & .006 & Positive Urgency & .177 & .048 \\
\hline
\end{tabular}

Note: ${ }^{1}$ STAI-B $=$ State-Trait Anxiety Inventory (Trait), ${ }^{2}$ BDI $=$ Beck Depression Inventory, ${ }^{3}$ UPPS $=$ UPPS Impulsive Behavior Scale. 